\title{
تأثير استيعاب مادة المطالعة لمهارة الكلام
}

\author{
Eko Bowo Wicaksono ${ }^{*}$, Alfy Mamduh Nuruddin ${ }^{2}$ \\ Universitas Darussalam Gontor \\ 1* ${ }^{*}$ kkobowo2u@gmail.com, ${ }^{2}$ mamduhtop@gmail.com
}

\begin{abstract}
The research aims to: (1) Determine the ability of class 3 students Intensive KMI Gontor Campus 2 in mastery of the Muthala'ah Uslub (2) Knowing the ability of Class 3 students Intensive KMI Gontor Campus 2 in speaking ability (3) Knowing whether there is an influence ability in mastery of Uslub Muthala'ah on the speaking ability of grade 3 students Intensive Kulliyatul Mu'allimin AlIslamiyah Pondok Modern Darussalam Gontor Campus 2 Siman Madusari Ponorogo, East Java Academic Year: 1440 - $1441 \mathrm{H}$. This research applied quantitative method. The data collection technique used are (1) Test results, to know the ability of students in class 3 intensive KMI Gontor campus 2 in speaking skill. (2) Documentations, to get data on the value of learning achievement in muthola'ah lessons and the general description about the institutions. The data analysis used product moment correlation with a significance level of $5 \%$ or $1 \%$ with 73 degrees of freedom (df) 73 . According to the analysis, it reveals that (1) mastery of muthola'ah grade 3 students Intensive KMI Gontor campus 2 school year: 1440-1441 is good with a grade of 5.58. (2) speaking ability of students in Intensive Class 3 KMI Gontor campus 2 academic year: 1440-1441 is very good with a score of 7.01. (3) There is a significant influence between mastery of muthola'ah and the speaking ability of grade 3 students Intensive KMI Gontor campus 2 academic year: 1440-1441, this was indicated by a value of 0.851 which was greater than the value of " $\mathrm{r}$ " in the table $5 \%$ and $1 \%$, namely 0.232 and 0.302 .
\end{abstract}

Keywords: Influence; Mastery of Muthola'ah; Speaking Skills.

$$
\begin{aligned}
& \text { البـاحثين واللغـويين أنّ اللغــة العربيـة لهـا شـأن عظــم }
\end{aligned}
$$

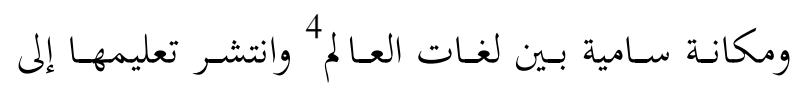

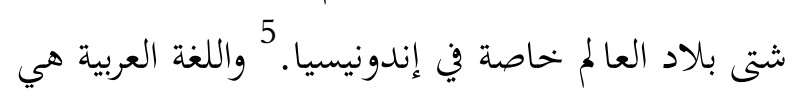

$$
\begin{aligned}
& \text { إحدى اللغات التي استخدمها طلاب معهد دار السلام } \\
& \text { كونتور الحرم الثاني للتربية الإسلامية الحديثة وجعلها لغة }
\end{aligned}
$$

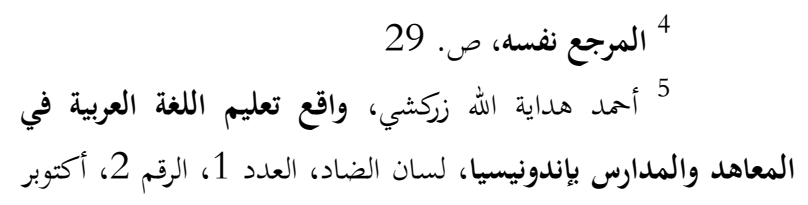$$
\text { 2014، ص. } 11
$$

$$
\begin{aligned}
& \text { اللغة هي الألفاظ والتراكيب التي يعبر بها كل }
\end{aligned}
$$

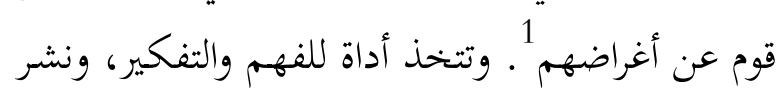

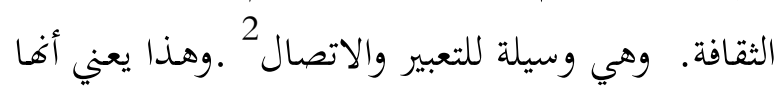

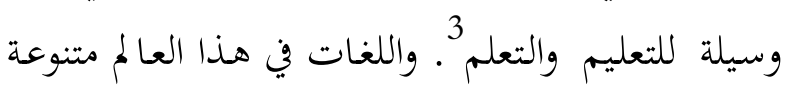

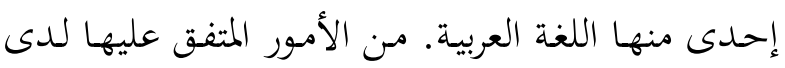$$
\text { 1 مصطفي الغلايين، جامع الدروس العربية،(القاهرة: دار }
$$$$
\text { التوقيفية للتراث،2010)، ص. } 7
$$$$
2 \text { ديفي إيكا ديانتيكا، العلاقة بين اللغة والثقافة، الناس، }
$$

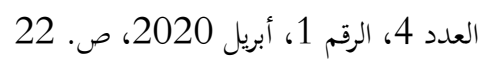$$
\text { 3 علي أحمد، تدريس فنون اللغة، (الرياض: دار الشواف صاف }
$$$$
\text { للنشر والتوزيع، 1991)، ص. } 27
$$ 
والإدراك لدى التلاميذ. والمطالعة الجيدة من خير

الوسائل التي تعين التلاميذ على حسن التعبير نتيجة لما يعلق بذهنهم من الأفكار والعبارات والأساليب المختلفة. وهي تنمي ثروة التلاميذ اللغوية في الألفاظ والأساليب والأفكار ويؤثر في تربية التلاميذ تأثيرا عمليا بالاستعمال في أحاديثهم يوميا فيدركون قيمتهم. ويقبلون عليه وعلى تحصيل سواه إحساسا فائدة في حياتم العملية.

الكــلام فــنّ نقــل الاعتقــادات والعواطــف

والاتجاهات والمعاني والأفكار والأحداث من المتكلم إلى لى

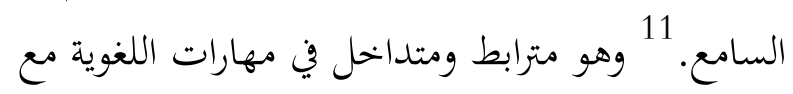
فروع اللغة الأخرى إلى حد كبير، فهو مترابط مع القواعد النحوية الصرفية، مترابط مع الإملاء والخطط،

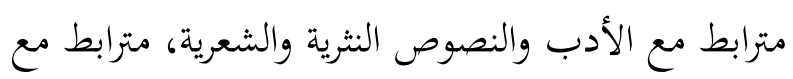

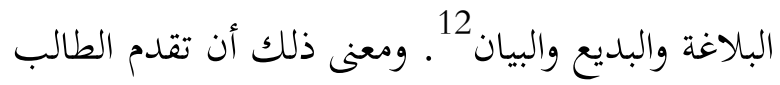
ونموه في أحد هذه الفروع اللغوية، هو بالتالي تقدم للطالب نموا له في مهارة الكلام. من أهم مهارة الكلام وهي النطق الصحيح لللأصوات العربية وإنتاج الأصوات

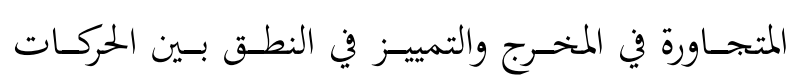
الطويلة والقصيرة والتعبير الصحيح عن الحاجـة في جملة

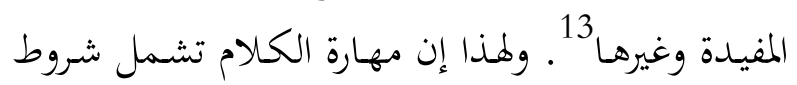
الكـلام الصـحيح للتلاميـذ في نطق اللغـة العربيـة كمـا تعلموا في المواد العربية مثل المطالعة.

11 سيف المصطفى وأرين بداية، تأثير استخدام وسيلة التعليم

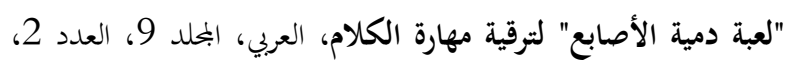
2017، ص. 188 12 أحمد فؤاد، المهارات اللغوية ماهيتها وطرائق تدريسها،

$$
\text { (الرياض: دار المسلم، 1992)، ص. } 87 \text { المرجع نفسه، ص. } 88 \text { المداد، المبات } 87
$$

رسمية وحديثا يوميا إلى جانب اللغة الإبحليزية6. واللغة العربية لغة التعليم في المواد الدراسية الدينية واللغوية. إن نشاط التعليم اللغوي لا بد أن يكون

موجها إلى تنمية المهارات اللغوية الأربعة مرتبة، وهي :

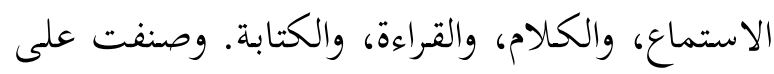
أخها مهارات شفهية(الاستماع والكلام) وأخرى مهارات مرئية ( القراءة والكتابة ) وصنفت على أهنا مهارات إنتاجية وأخرى مهارات استيعابية . . واستخد المدرسون هذه المهارات في تعليم اللغة العربية حتى يستوعبون الطلاب ويرتفعون كفاءقم في اللغة العربية. كانت المطالعة مادة دراسية لرفع مستوى كفاءة الطلاب في القراءة والكلام والكتابة. 8 إن الغرض مادة دران منها هو تعويد التلاميذ على فهم ما يقرأون من الكتب

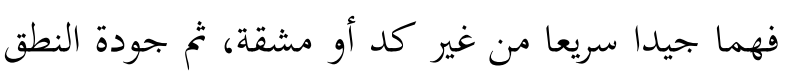
وحسن الإلقاء حتى يسهل السامع أيضا على فهم الآراء

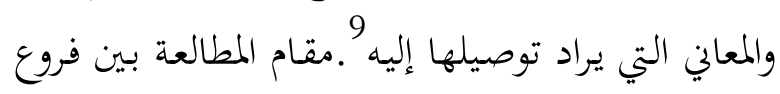

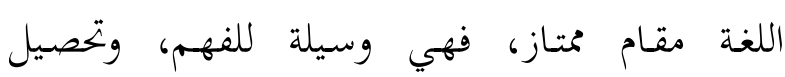
المعلومات، وتزويد الثقافات المختلفة وتنمية الثروة اللغوية الـ وهي من أعظم الوسائل لتربية ملكة الانتباه

${ }^{6}$ Gontor dan Bahasa. Artikel Gontor News, dalam situs https://www.gontor.ac.id/ (diakses pada 21 Januari 2019).

$$
\begin{aligned}
& \text { 7محمد الأوراغي، اللسانيات النسبية وتعليم اللغة العربية، } \\
& \text { (دار الأمان: 2010)، ص. } 177
\end{aligned}
$$

8 سيد أحمد ناصح، علاقة استيعاب مادة المطالعة على كفاءة الإنشاء لطلاب الفصل العاشر بمعهد دار الفكر الإسلامي

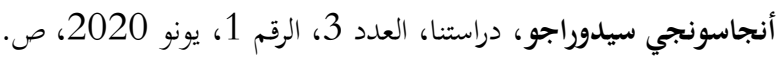

9 طـه علدي حســن، اللغــات العربيـة مناهجهـا وطرائسق

$$
\text { تدريسها، (دار الشروق: 2005)، ص. } 169
$$

10 طه علي حسين، اتجاهـات حديثة في تسدريس اللغـة

$$
\text { العربية، (عالم الكتب الحيث:2004)، ص.437 }
$$


إن هذا البحث من البحث الميداني الوصفي

الكمي(15) (Quantitative Descriptive Research فأتى مصادر البيانات من بحتمع البحث والعينة. العينة المستخدمة هي تلاميذ الصف الثالث التكثيفي بكلية المعلمين الإسلامية بمعهد دار السلام كونتور الحرم الثاني الذي بلغ عددهم 75 تلميذا. وأساليب جمع البيانات الإسيه

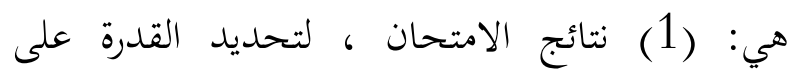
التحدث تلاميذ الصف الثالث التكثيفي بكلية المعلمين الإسلامية بمعهد دار السلام كونتور الحرم الثاني. (2). الوثائق المكتوبة، للحصول على بيانات حول نتائج اختبارهم في مادة المطالعة وللحصول على بيانات حول الوصف العام لهذا المعهد. واستخدم الباحث لتحليل البيانات تقنية الارتباط اللحظي للمنتج بمستوى أهمية 5\% أو 1\% مع 73 درجة حرية (df). عدد مجتمع طلاب الفصل الثالث التكثيفي بكلية المعلمين الإسلامية بمعهد دار

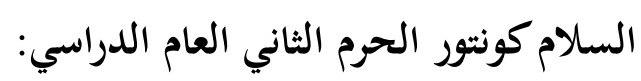
1441-1440 الجدول رقم (1)

\begin{tabular}{|c|c|c|}
\hline المحمع & الفصل & الرقم \\
\hline 29 طالبا & B الثالث التكثيفي & 1 \\
\hline 25 طا لبا & C الثالث التكثيفي & 2 \\
\hline 21 طا لبا & Dالثالث التكثيفي & 3 \\
\hline
\end{tabular}

${ }^{15}$ Sugiyono, Statistik Nonparametris Untuk Penelitian, (Yogyakarta: Alfabeta. 2015), p. 61

كلية المعلمين الإسلامية، وثيقة كلية المعلمين الإسلامية، 16

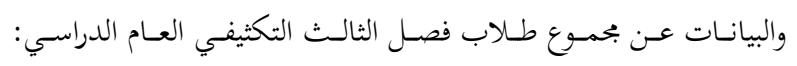
1441-1440، (كونتور : غير المنشور.2017 ). ص. صـو 5
ومعهد دار السّلام كونتور الثّاني بكليّة المعلّمسين

الإسلاميّة هو أحد فروع معهد دار السّلام كونتور للتربيّة الإسـلاميّة الحلديثـة. وكمــا عرفنـا أنّ معهـد دار السّـلام كونتور الثّانى يتكوّن بعض نشاطاها الرسميّة مـن اللّغة

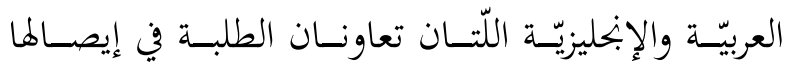
وتنفيذها. واللّغة عنصـر مـن العناصر المهمّة للطّلبـة في

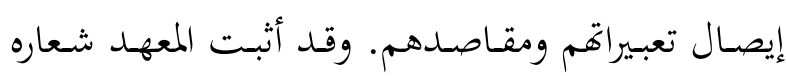
"اللّغة تاج المعهده" فإنّه قد يكون منهجا أساسيا لتعليم اللّغة وامتثالا لبعض المدارس الأخرى.

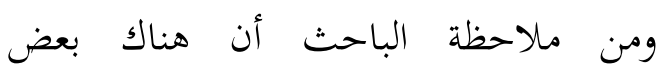
المشكلات في مهارة الكالام العربي لطلاب الفصل الثالث التكثيفي. أهم لم يستوعبوا مادة المطالعة جيدة، مع أهم تعلمواها سنتين 14 . وأن طلاب الفصل الثالث التكثيفي تعلموا مادة المطالعة قدر سنتين في الفصل الأول التكثيفي والثالث التكثيفي. فظهر أثر استيعاب مادة المطالعة في هذه السنة بكثير المعرفة عن الأساليب الكثيرة من الموضوعات. واستخدموا في محادثنهم اليومية. ومن هذه القضية، أراد الباحث البحث عن تأثير استيعاب مادة المطالعة في مهارة الكلام لطلاب الفصل الثالث التكثيفي بكلية المعلمين الإسلامية معهد دار السلام كونتور الحرم الثاني مادوساري سيمان فونوروكو جاوي الشرقية العام الدراسي : 14401441

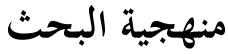

14 الملاحظة من الامتحان الشفهي في المادة المحادثة لطلاب

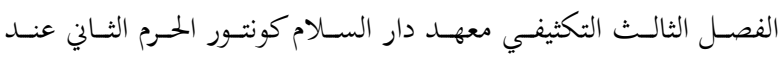

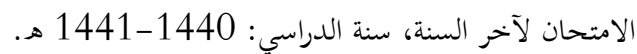




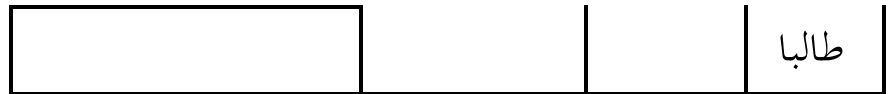

$$
\text { عرض البيانات الخاصة }
$$

أ) علاقة استيعاب مادة المطالعة ومستوى مهارة

$$
\text { الكلام }
$$

لكشـف اسـتيعاب مـادة المطالعـة في مهـارة

الكلام لطلاب الفصل الثالث التكثيفي بكلية المعلمـين

الإســلامية معهــــد دار الســام كونتـور الحـــرم الثـاني

مادوســاري سـيمان فونوروكــو جـاوي الشـرقية العـام

الدراسي : 1440-1441 هـ. عقد الباحث الاختبار

وقارن الباحث لاستيعاب مادة المطالعة ومهارة الكلام.

فعزم الباحـث على مقارنـة النتائج مـن هـذين المتغيرين،

$$
\text { وهي كما يلي } 18
$$

بالنظر إلى بحموع النتائج في استيعاب مادة المطالعة

وباستخدام الرمز الأول للكشف عن معدل كما يلي:

$$
\begin{array}{r}
X=\frac{\sum x}{N} \\
5,58=\frac{419}{75}
\end{array}
$$

فحصل الباحث على النتيجة 58،

نظـرا إلى معيـار النتـائج، فالنتيجــة لطـلاب

الفصـل الثالـث التكثيفـي بكليـة المعلمـين

$$
\text { الإسلامية جيدة. }
$$

بـالنظر إلى بحمـوع النتـائج في مهـارة

الكلام وباستخدام الرمز الأول للكشف عن

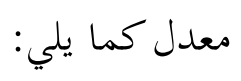

$$
X=\frac{\sum x}{N}
$$

18 18ائق المكتوبة من الملحق، رقم : 04/D/5/2017 \begin{tabular}{|l|l|}
\cline { 2 - 2 } & البمموع 75 \\
\hline
\end{tabular}

العينة هى جزء من بحتمع الأصلي، اختارها

الباحث بأساليب مختلفة، تضم عددا من الأفراد من

المجتمع الأصلي كما قال Suharsimi Arikunto إن

كان عدد المحتمع أكثر من 100 يجيوز الباحث أن

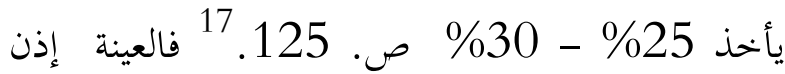

تمثل البحتمع الأصلي وتحقق أغراض البحث ويعني الباحث عن دراسة المحتمع الأصلي. أخذ الباحث العينة من جميع طلاب الفصل الثالث التكثيفي بكلية المعلمين

\begin{tabular}{|c|c|c|c|c|}
\hline الرقم & الفصل & المجموع & المعدل & العينة \\
\hline & الثالث & & & 29 \\
\hline 1 & B التكثيفي & 29 طالبا & $\% 100$ & طالبا \\
\hline & الثالث & & & 25 \\
\hline 2 & C التكثيفي & 25 طالبا & $\% 100$ & طالبا \\
\hline & الثالث & & & 21 \\
\hline 3 & التكثيفي & 21 طالبا & $\% 100$ & طالبا \\
\hline \multicolumn{2}{|c|}{ المجموع } & 75 طالبا & $\% 100$ & 75 \\
\hline
\end{tabular}
الإسلامية العام الدراسي: 1440-1441هـ لأن عدد المحتمع أقل من 100.

$$
\text { الجدول رقم (2) - (2) }
$$

العينة من عدد مجتمع طلاب الفصل الثالث

التكثيفي بكلية المعلمين الإسلامية بمعهد

دار السلام كونتور الحرم الثاني العام الدراسي: 1440-1441هـ

17 Suharsimi Arikunto. Manajemen

Penelitian. ( Jakarta: PT. Rineka Cipta.2000),p.125. 
2. الطلاب الذين حصلوا علي درجة جيد جدا

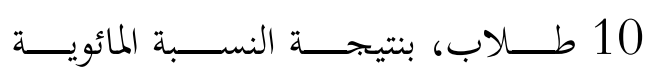

$$
\text { \%13،33 }
$$

3. الطلاب الذين حصلوا علي درجة جيد 29

طالبا، بنتيجة النسبة المائوية 67،38 \%

4. الطلاب الذين حصلوا علي درجة مقبول 24

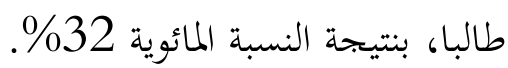

5. الطلاب الذين حصلوا علي درجة ضعيف 9

طلاب، بنتيجة النسبة المائوية 33، 13\%

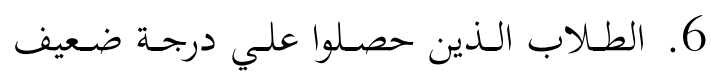

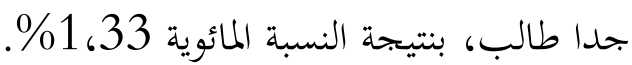

هذذا البيان يري الباحث أنّ مقدرة الاختبار عن لبن.

استيعاب مادة المطالعة لطلاب الفصل الثالث التكثيفي

بكلية المعلمين الإسلامية معهد دار السلام كونتور الحرم

الثاني مادوساري سيمان فونوروكو جاوي الشرقية العام

الدراسي : 1440-1441 هـ متوسطة.

$$
\text { الجحدول رقم (4) }
$$

النتائج المحصول عليها في مهارة الكلام لطلاب

\begin{tabular}{|c|c|c|c|c|}
\hline$\%$ & الطلاب & البيان & النيجة & الرقم \\
\hline 22.67 & 17 & متمتاز & 8 & 1 \\
\hline $58 ، 66$ & 44 & جداد & 7 & 2 \\
\hline 16 & 12 & جيد & 6 & 3 \\
\hline 2.67 & 2 & مقبول & 5 & 4 \\
\hline $\begin{array}{c}100 \\
\%\end{array}$ & 75 & \multicolumn{3}{|c|}{ المجموع } \\
\hline
\end{tabular}

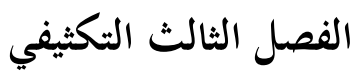

$$
7,01=\frac{526}{75}
$$

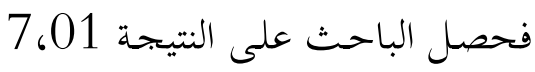

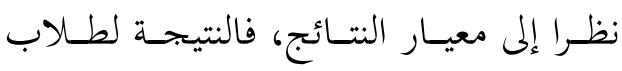

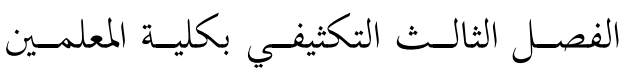

$$
\text { الإسلامية جيد جدا. }
$$

تحليل البيانات

وصل الباحث إلى تحليل البيانات لتأثير الكفاءة

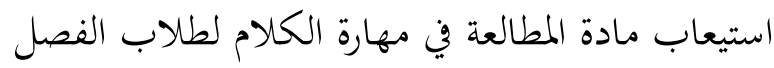
الثالث التكثيفي. وقد جمع النتائج فيما يلي:

\begin{tabular}{|c|c|c|c|c|}
\hline$\%$ & الطلاب & البيان & النتيجة & الرقم \\
\hline 6.27 & 2 & متتاز & 8 & 1 \\
\hline 13,33 & 10 & جيد & 7 & 2 \\
\hline 38,67 & 29 & جيد & 6 & 3 \\
\hline 32 & 24 & مقبول & 5 & 4 \\
\hline 12 & 9 & ضعيف & 4 & 5 \\
\hline 1,33 & 1 & & 3 & 6 \\
\hline$\% 100$ & 75 & & المج & \\
\hline
\end{tabular}
الجدول رقم (3)

النتائج المحصول عليها في كفاءة استيعاب مادة المطالعة

من البيانات المذكورة ففسر الباحث الأمور الآتية: 1. الطلاب الـذين حصـلوا علي درجـة الممتـازة

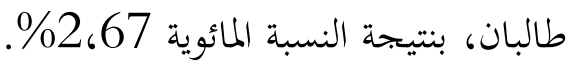


(0،232) و \% هي: (0،302)، بمعنى نتيجة

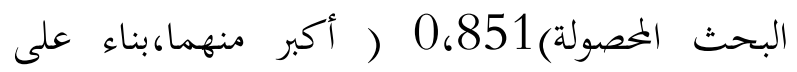

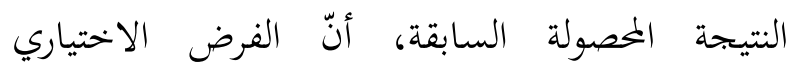
مقبول والفرض (Alternative Hypothesis) اللاغي(Null Hypothesis) مرفوض.

\section{مناقشة ونتائج البحث}

يتمثل تأثير استيعاب أساليب المطالعة في مهارة

$$
\text { الكلام كما يلي: }
$$

1. تعويد الطلاب جودة النطق وحسن الإلقاء

حتى يسهل على السامع أيضا فهم الآراء والمعاني التي يراد توصيلها إليه .

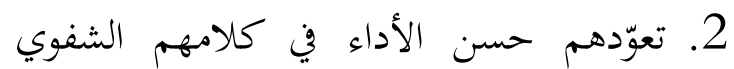

والتحريري والتزام النطق الصحيح والتعبير السليم والتفكير السديد والفهم الدقيق، كما أها أساس طبيعي لتنمية قدرقم على التذوق

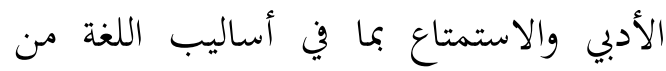
جمال فني وصور بارعة متعة.

3. خير الوسائل التي تعينهم على حسن بارة منعة. التعبير

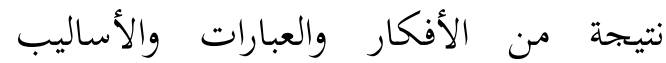
المختلفة. وهي تنمي وتؤثر في تربيةهم تأثيرا عمليا باستعمالها في أحاديثهم يوميا فيدركون قيمتهم. ويقبلون عليه وعلى تخصيل سواه إحساسا فائدة في حياقم العملية.

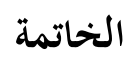

مؤسسا على هدف البحث ومما عرضه الباحث في

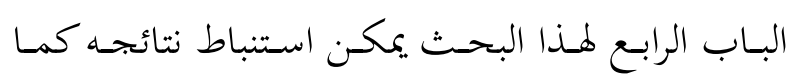

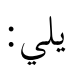

من البيانات المذكورة ففسر الباحث الأمور الآتية:

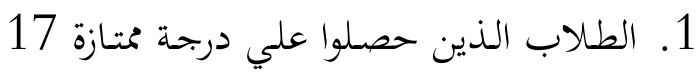
طالبا، بنتيجة النسبة المائوية 67،22\%. 2. الطلاب الذين حصلوا علي درجة جيد جـدا 44 طــلاب، بنتيجــــة النســـبة المائويسـة

$$
\text { \% 58،66 }
$$

3. الطلاب الذين حصلوا علي درجة جيد 12 طالبا، بنتيجة النسبة المائوية 16\%

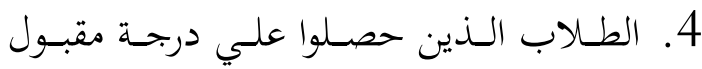
طالبان، بنتيجة النسبة المائوية 67،2\%. من البيان السابق أدخل الباحث هذه النتيجة إلى الرمز المبين لنيل النتيجة المحصولة من إحصاء تلازم

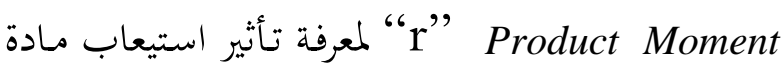
المطالعة على مهـارة الكـلام لطـلاب الفصـل الثالـث التكثيفي بكلية المعلمسين الإسلامية معهد دار السـلام

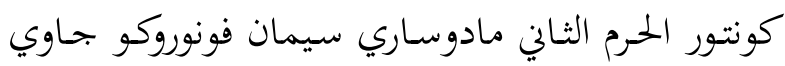

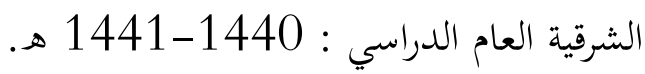
إن معرفة صحّة الفرد تبيّن عن طريقة معرفة الدّرجة الحرّيّة (Degree of Freedom)، وذلك بالرمز الآتية:

$$
\begin{aligned}
& \mathrm{N}-\mathrm{nr}=\mathrm{Df} \\
& \text { البيان: } \\
& \text { N } \\
& \text { nr }
\end{aligned}
$$$$
73=2-75=\mathrm{Df}
$$

بعدم وجود درجة حرية على نتيجة 73 فأخذا

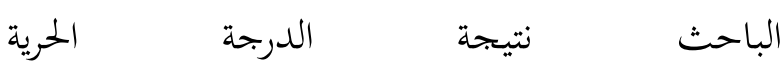
الأقرب بها يعني 70، فوجد الباحث في اللوحة (Df)

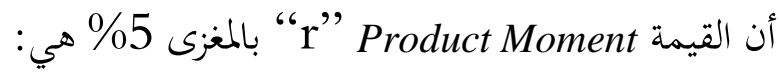


علي أحمد. 1991. تدريس فنون اللغة. الرياض: دار الشواف للنشر والتوزيع.

عمر الصديق. 2008. تعليم اللغـة العربيـة لنـاطقين

$$
\text { بغيرها. الدار العالمية. }
$$

فـتي علي. أساسسيات تعلسيم اللغــة العربيسة والتربيسة الدينية. مصر: دار الثقافة.

قسم المنهج الدراسي.2017. مـنهج الدراسي كليـة المعلمين الإسلامية. فونوروكو.

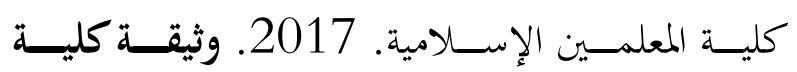

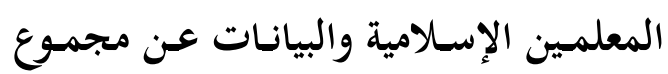

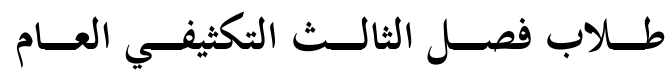

$$
\text { الدراسي: 1440-1441. فونوروكو. }
$$

محمد الأوراغي. 2010. اللسـانيات النسبية وتعليم

$$
\text { اللغة العربية. دار الأمان. }
$$

محمـــــفـران. 2006. البلاغــة فـي العلـم البيـان.

$$
\text { فونوروكو: دار السلام. }
$$

مصطفي الغلايين. 2010. جـامع الدروس العربيـة.

$$
\text { دار التوقيفية للتراث. }
$$

Anas Sudijono. 2014. Pengantar Statistik Pendidikan. Jakarta: PT. Raja Grafindo.

Gontor dan Bahasa. Artikel Gontor News, dalam situs https://www.gontor.ac.id/ (diakses pada 21 Januari 2015).

Sugiyono. 2015. Statistik Nonparametris Untuk Penelitian. Yogyakarta: Alfabeta.

Suharsimi Arikunto. 2000. Manajemen Penelitian. Jakarta: PT. Rineka Cipta.

Zarkasyi, Abdullah Syukri. 2000. Manajemen

Pesantren, Pengalaman Pondok Modern Gontor. Ponorogo: Trimurti Press.
1. كان استيعاب طلاب الفصل الثالث التكثيفي بكلية المعلمين الإسلامية معهد دار السلام كونتور الحرم الثاني مادة المطالعة جيد حيث حصلئ الإسلها النتيجة 58، 58

2. كانت مستوى طلاب الفصل الثالث التكثيفي

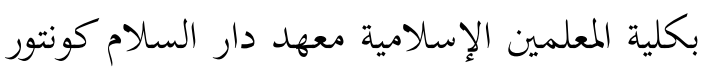

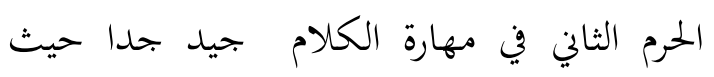

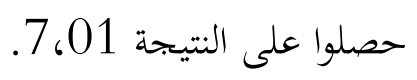

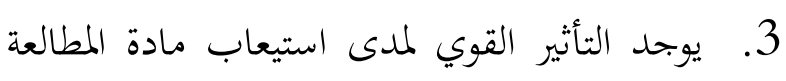
في مهارة الكلام لطلاب الفصل الثالث التكثيفي بكلية المعلمين الإسلامية معهد دار السلام كونتور الحرم الثاني من الحساب الإحصائي أنّ النتيجة

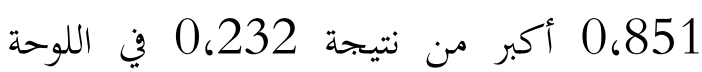
فصار الفرض الاختياري مقبولا قائمة المراجع والمصادر القرآن الكريم طه علي حسين. 2005. اللغـات العربيـة مناهجها وطرائق تدريسها. دار الشروق.

2004. اتجاهـات حديثة في تدريس دارس اللغة العربية. عالم الكتب الحيث.

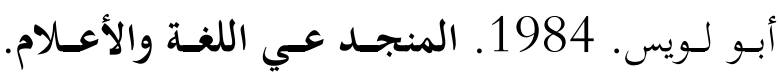

$$
\text { بيروت: دار المشرق. }
$$

أحمد فؤاد. 1992. المهارات اللغوية ماهيتها وطرائق تدريسها. الرياض: دار المسلم.

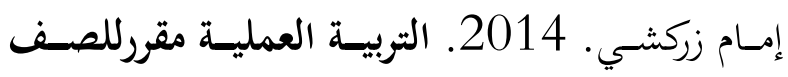
السادس. طبعة الرابع. فونوروكو: دار السلام لمباعة والنشر. 